\title{
The carbon budget of the Himalayan orogeny from source to sink
}

CHRISTIAN FRANCE-LANORD ${ }^{1}$, LOUIS DERRY ${ }^{2-3}$, SARAH J. FEAKINS ${ }^{4}$, ALBERT GALY ${ }^{1}$, VALIER GALY ${ }^{5}$, FREDERIC GIRAULT $^{3}$ MAARTEN LUPKER $^{6}$, ASWIN TACHAMBALATH ${ }^{1}$

${ }^{1}$ CRPG, CNRS-Université de Lorraine, Nancy, France.

${ }^{2}$ Cornell, Ithaca, NY, USA.

${ }^{3}$ WHOI, Woods Hole MA, USA.

${ }^{4}$ University of Southern California, Los Angeles, CA, USA.

${ }^{5}$ IPG Paris, France.

${ }^{6}$ ETHZ, Zürich, Switzerland, USA.

Over the Neogene, the evolution of the Himalayan orogen modified the continental distribution, topography and climate with a significant impact on the global biogeochemical cycles. The development of the highest mountain range coupled to the intense monsoonal precipitation regime generated an intense erosional flux that enhanced both organic carbon burial and silicate weathering. In the meantime, crustal metamorphism generated decarbonation reactions that release $\mathrm{CO}_{2}$ to the atmosphere. The latter can be documented through direct observation of $\mathrm{CO}_{2}$ degassing in the modern range.

The largest part of the erosion flux was exported to the Bengal Fan, accumulating a long-term archive. These sediments document the nature of eroded formations in the Himalaya and their weathering, and they directly record organic carbon fluxes. The recent IODP Expedition 354 in the Bengal Fan generated a relatively complete record at the Neogene time-scale. Estimating paleo-weathering requires careful characterization of the source-rock composition, include Himalayan and Transhimalayan lithologies with various degrees of maturity. Weathering budget is also hampered by the estimation of sulphide oxidation reactions which are actually only estimated on the modern system. Organic carbon burial is directly estimated from concentration of organic matter in the fan which is controlled by the grain size of the sediment. In addition macroscopic wood fragments revealed to be widespread in the fan and represent an additional sink [A]. The fan also accumulates fine grain diagenetic carbonates that overall represent 1 to $2 \%$ of the whole sediments.

While important uncertainties remain, the relative importance of the different processes appear established with organic carbon burial representing the dominant sink of carbon associated with erosion.

[A] Lee et al. PNAS, 2019 